\title{
How Do Analyst Recommendations Respond to Major News?
}

\author{
Jennifer Conrad, Bradford Cornell, Wayne R. Landsman, and \\ Brian R. Rountree*
}

\begin{abstract}
We examine how analysts respond to public information when setting stock recommendations. We model the determinants of analysts' recommendation changes following large stock price movements. We find evidence of an asymmetry following large positive and negative returns. Following large stock price increases, analysts are equally likely to upgrade or downgrade. Following large stock price declines, analysts are more likely to downgrade. This asymmetry exists after accounting for investment banking relationships and herding behavior. This result suggests recommendation changes are "sticky" in one direction, with analysts reluctant to downgrade. Moreover, this result implies that analysts' optimistic bias may vary through time.
\end{abstract}

\section{Introduction}

In this study, we examine how analysts' recommendations respond to public information shocks, using large price changes as a proxy for the shocks (Ryan and Taffler (2004)). We develop hypotheses about analysts' responses to public news based on various assumptions regarding the information analysts possess and the incentives they face. We then estimate empirical models of recommendation levels, conditioning on the sign of the information shock, to determine which hypothesis is most consistent with the data. The hypotheses we consider begin with the assumption that analysts' recommendations reflect price-to-value comparisons and a belief that the market is informationally efficient. In the first hypothesis (H1), analysts are unbiased but have no informational advantage relative to the market, in which case we predict that, on average, a large stock price

\footnotetext{
*Conrad, j_conrad@unc.edu, Department of Finance, University of North Carolina at Chapel Hill, Chapel Hill, NC 27514; Cornell, bcornell@hss.caltech.edu, California Institute of Technology, Division of the Humanities and Social Sciences, Pasadena, CA 91125; Landsman, wayne_landsman@unc.edu, Department of Accounting, University of North Carolina at Chapel Hill, Chapel Hill, NC 27514; Rountree, rountree@ rice.edu, Department of Accounting, Rice University, Houston, TX 77005. The authors thank IBES for providing IBES analyst recommendations. The authors also thank workshop participants at the 2002 American Accounting Association Annual Meeting, UCLA, University of Chicago, the 2002 London Business School Summer Symposium, University of Iowa, and University of North Carolina, Ivo Welch (associate editor and referee), and Hendrik Bessembinder (the editor). Conrad and Landsman acknowledge financial support from the Center for Finance and Accounting Research at the University of North Carolina at Chapel Hill.
} 
movement will leave the probability of a change in recommendation level unaffected. In both the second (H2) and third (H3) hypotheses, analysts believe they have private information relative to the market. However, in H3, analysts may have conflicts of interest (pressure from their firms) that affect their recommendations. ${ }^{1}$ Where no conflict of interest exists (H2), we predict that, on average, analysts will downgrade (upgrade) in response to positive (negative) price shocks; that is, at least a portion of the analysts' private information is revealed by the price movement. Although there is a predicted difference in the direction of the response, we predict no difference in the magnitude of the response to positive and negative stock price shocks under $\mathrm{H} 2$.

In $\mathrm{H} 3$, a conflict of interest may exist if the analyst receives negative private information. In this case, the analyst would ordinarily prefer to downgrade the stock to maintain the optimal level of optimism and perceived accuracy, but is prevented from doing so because of business pressure. A sufficiently large negative shock may relieve the conflict of interest because the market price reveals a portion of the analyst's perceived private information, thereby permitting the analyst to downgrade. No conflict of interest exists if the analyst believes that she has positive private information. Thus, if $\mathrm{H} 1$ or $\mathrm{H} 2$ is correct, then the effect on recommendation levels will be symmetric following positive and negative information shocks, although $\mathrm{H} 1$ would also be consistent with no response. In H3, we predict the possibility of an asymmetric response.

The results demonstrate that analysts respond to large price changes by changing their recommendations. That is, among the sample of analysts' recommendations, the probability of observing a change in the recommendation level is much higher conditional on a large stock price event in the preceding three days. These results are not consistent with $\mathrm{H} 1$, i.e., with analysts behaving as if they have no private information. Second, following large stock price increases, analysts are equally likely to upgrade or downgrade, i.e., on average analysts react as if fundamental values and market prices move in tandem. Following large stock price declines, however, analysts are much more likely to downgrade a company's stock. The asymmetry is also present when we examine only "interior" recommendation levels, from which analysts can either upgrade or downgrade securities. The observed asymmetry is consistent with analysts' recommendations before the public information shock is attributable, at least in part, to some other force such as pressure from their employers.

The higher probability of recommendation downgrades following large negative return events also is consistent with the theory of information cascades. In this case, the negative return event shatters the optimistic consensus (Bikhchandani, Hirshleifer, and Welch (1992)). However, the asymmetry in the analysts' responses to negative return events cannot be simply attributable to analyst herding. In particular, the evidence reveals that these negative return events are significant determinants of analysts' recommendation levels even after controlling for the tendency of analysts to respond following other analysts' recommendation changes. Overall, the findings suggest that recommendations are differentially

\footnotetext{
${ }^{1}$ Our definition of private information encompasses both the presence of information not known to the public as well as the ability to interpret documented regularities better than the general public. Of course, an analyst might believe that he has private information when he does not.
} 
"sticky" - analysts appear to use large stock price drops to realign their optimal level of optimism and accuracy.

We also conduct a number of robustness checks on our results. First, an examination of 20- and 60-day market-adjusted returns commencing immediately after the three-day price shock event show no systematic evidence of price continuation or reversals. This suggests that the price shock we use as our conditioning variable does not represent an under or over market reaction. Thus, the asymmetry does not appear to be a prediction of a correction to an over (under) price reaction. Second, we re-estimate the probit model on two subsamples to determine if the asymmetry persists when we control for the presence and nature of the news. The first subsample comprises the set of recommendations around earnings announcements. We find that, controlling for earnings surprises, downgrades are still more likely to follow negative price shocks, but upgrades and downgrades are equally likely to follow positive price shocks. In the second subsample, we identify a small set of large return events for which we could identify no contemporaneous news release. The asymmetry persists for this sample as well.

We also find that upgrades are more likely if there is a historical investment banking relationship between the brokerage firm making the recommendation and the firm for which the recommendation is issued. Analysts also tend to respond in the same direction as other analysts who recently changed their recommendations. However, these results do not explain the asymmetry since their effects are present in both the positive and negative return samples.

The remainder of the paper is organized as follows. Section II discusses the related literature. In Section III, we develop our hypotheses. Section IV describes the nature of the data, the sample selection criterion, and the empirical framework. The empirical results are presented in Section V. Section VI discusses the implications of the results. Section VII examines post-event returns, while Section VIII summarizes the paper.

\section{Related Literature}

Unlike analysts' earnings forecasts, which are short-term point estimates, analysts' recommendations can be considered more analogous to capital budgeting decisions. For instance, Womack (1996) states that stock recommendations are akin to an analyst concluding that, "I have analyzed publicly available information, and the current stock price is not right" (p. 164). This suggests that analysts develop explicit (or implicit) valuation models. If the market price is sufficiently below the true value indicated by the model, the stock is accorded a buy recommendation; when the market price is above the model value, the stock is given a sell recommendation.

Both academics and practitioners have questioned the view that analysts' recommendations are simple valuation decisions. First, investment banking relationships can potentially bias analyst recommendations (Lin and McNichols (1998)). Consistent with this, Barber, Lehavy, and Trueman (2004) show that independent research analysts tend to outperform analysts employed by investment banks, and that a large source of the investment banks' underperformance is a reluctance to downgrade stocks that had recently issued equity. Thus, analysts 
have mixed incentives. On the one hand, they want to produce accurate reports to satisfy investors. On the other hand, they have an incentive to produce positive reports to generate (or retain) investment banking business from the companies being evaluated. One indication of these conflicting interests is the well-known upward bias in the distribution of recommendations documented by Stickel (1995) and others. ${ }^{2}$

Second, some empirical research contradicts the view that analyst recommendations are based primarily on fundamental valuation models. Bradshaw (2004) examines the correlation between analyst recommendations and the ratio of fundamental firm value to market price. Bradshaw calculates fundamental value by substituting analysts' consensus earnings forecasts into the residual income version of the discounted cash flow model developed by Ohlson (1995). Surprisingly, he finds that analysts' recommendations are more (less) favorable for stocks with low (high) value relative to price. This finding is the reverse of what the capital budgeting interpretation predicts. However, Bradshaw's results are consistent with the survey work of Block (1999). Based on a survey of analysts, Block reports extremely low reliance on valuation methods in the formation of stock recommendations. ${ }^{3}$ Third, Welch (2000) finds significant evidence of herding toward the consensus among analysts, which is not related to the accuracy of the consensus. Thus, analysts do not tend toward the consensus based on fundamental information.

Individual case studies point to a possibly complex relation between the arrival of market information and changes in analyst recommendations. For instance, Cornell (2001) finds a puzzling relation between the innovations in market value and changes in analyst recommendations. Cornell examines the market reaction to an apparently minor news announcement by Intel that, nonetheless, resulted in a 30\% drop in the company's stock price and destroyed $\$ 125$ billion in shareholder wealth. Following the news announcement and the subsequent price drop, many analysts revised their recommendations downward, some by several rating classifications. Not one analyst increased his or her recommendation. If analyst recommendations were based on a comparison of value to price, this reaction implies that all analysts believed that fundamental value fell by more than the $\$ 125$ billion drop in market capitalization. However, Cornell argues that there was not enough information in the news release to justify the observed drop in price; that is, he argues that the change in fundamental value was less than the drop in price. As with Bradshaw and Block, Cornell's conclusion would suggest that in downgrading the company following the price decrease, Intel analysts did not rely on present value models.

\footnotetext{
${ }^{2}$ Following the collapse of technology stock prices in 2000 , the conflict of interest issue became the focus of intense debate in the financial press (e.g., Tully (2001)) and several lawsuits. This perceived conflict of interest has led to increased scrutiny of analysts' investment practices by the Securities and Exchange Commission and states' attorneys general (e.g., see Opdyke (2001) and The New York Times, May 24, 2002).

${ }^{3}$ Interestingly, although Bradshaw (2004) finds that fundamental valuation models are not reliable predictors of analyst recommendations, he does find that heuristic valuation models (such as PEG ratios) have significant explanatory power, despite the fact that PEG ratios are not better predictors of future returns than value to price ratios.
} 
To date, there has been little research on the determinants of analysts' recommendation changes, and this work tends to focus on the relation between earnings announcements and recommendation changes (e.g., Bradshaw (2004) and Finger and Landsman (2003)), recommendation changes and subsequent stock returns (e.g., Green (2006) in this issue, Womack (1996), Jegadeesh, Kim, Krische, and Lee (2004)) or analysts' herding behavior (e.g., Welch (2000), Hong, Kubik, and Salomon (2000)). In terms of setting recommendation levels, findings in Hong and Kubik (2003) show that analysts are rewarded for both optimism and accuracy, which suggests that analysts trade off reputation (which is based on accuracy) and bias. Presumably, anything that affects the comparison of public price and private value will cause the analyst to change her recommendation while maintaining the optimal trade-off. However, if the analyst perceives the market price as too high relative to her private valuation, she may be reluctant to downgrade the stock (because of pressure from her company), causing the optimistic bias inherent in her recommendation to become larger. That is, there could be a dynamic component to the trade-off between accuracy and optimism. In this example, the dynamic component depends on the sign of the difference between her private valuation and market price. As market prices change in response to positive and negative information shocks, the analyst may change her recommendation to reflect a new optimal optimism/accuracy trade-off.

\section{Hypotheses}

In the first hypothesis, H1, we consider the possibility that analysts do not believe that they have private information and, consequently, make no value-to-price comparisons when setting recommendations. ${ }^{4}$ In this setting, a sharp change in stock price can neither reflect analyst private information nor have any systematic effect on analysts' recommendations.

In the second and third hypotheses, $\mathrm{H} 2$ and $\mathrm{H} 3$, we assume that analysts believe that they have private information and use value-to-price comparisons when setting recommendations. Following Hong and Kubik (2003), we also assume that analysts are rewarded based on accuracy and optimism. As a result, analysts set recommendations in a way that reflects an optimal trade-off between those two competing objectives. In $\mathrm{H} 2$, we assume that observed stock price changes are the result of revelation of at least a portion of analysts' perceived private information. As a consequence, when a portion of an analyst's private information is revealed, she may reset the recommendation to reflect the new value-to-price comparison. Under this hypothesis, therefore, we expect to see a downgrade following a price increase, and an upgrade following a price decrease. In addition, under H2, we assume that the well known (Stickel (1995)) recommendation bias is time invari-

\footnotetext{
${ }^{4}$ In the absence of private information, recommendations may serve the purpose of generating goodwill among the firm's clients and potentially investment banking business from the covered firms. For example, The Wall Street Journal quoted Mary Meeker (an analyst at Morgan Stanley Dean Witter) as saying "my highest and best use is to help MSDW win the best Internet IPO mandates ... and then to let them work their way through our powerful research and distribution system."
} 
ant. As a result, the magnitude of the effect on recommendation levels should be symmetric in the sign of the price shock. ${ }^{5}$

In H3, we assume that the optimistic bias in analysts' recommendations can change through time. In particular, because of conflicts of interest arising from pressure from the analyst's employer, the optimistic bias may be more severe when the analyst believes that she has negative private information. In this case, the private information of the analyst and the subsequent value-to-price comparison suggests that she downgrade the stock, but she cannot. That is, the optimistic bias has become larger-in fact, unacceptably so in the absence of the conflict of interest. This hypothesis is consistent with the empirical evidence presented in Welch (2000), which shows that herding is more pronounced in up-markets. As a consequence, up-markets may be less efficient at collecting information (e.g., Houston, James, and Karceski (2006) in this issue) and consequently may be more fragile-information shocks in such a market may have a larger impact. If enough of the analyst's perceived private information is revealed so as to result in a sufficiently large negative stock price revision, this may relieve the conflict of interest with no requirement of action on the analyst's part. If not, then the fragile consensus may be broken, and the analysts will be more likely to downgrade following a price decline.

When the analyst believes that she has positive private information, the subsequent value-to-price comparison suggests that she upgrade the stock, and because there is no conflict of interest, she is free to do so. Thus, as in $\mathrm{H} 2$, when the analyst's private information is subsequently revealed, causing a positive stock price revision, the analyst will either take no action if her information is incompletely revealed or downgrade if it is fully revealed. Thus, relative to $\mathrm{H} 1$ and $\mathrm{H} 2$, $\mathrm{H} 3$ is the only one that predicts the possibility of an asymmetric response on the part of analysts in terms of changing recommendations following negative and positive stock price events. The asymmetry is attributable to a stickiness in the downgrades that is the result of a conflict of interest.

\section{Sample Selection and Research Design}

\section{A. Construction of Sample}

Construction of the sample begins with the IBES U.S. Recommendations database, which spans the years 1993-2000. ${ }^{6}$ Each observation in the database represents the issuance of a recommendation by a particular brokerage firm for

\footnotetext{
${ }^{5}$ Stock price change events do not necessarily comprise the full extent of analysts' private information. Only if the price movement is sufficiently large will it cause the analyst to change her recommendation.

${ }^{6}$ We considered the use of changes in analysts' target prices rather recommendations as our dependent variable. For our sample, we examined the relation between changes in analysts' recommendation and percentage changes in corresponding target prices in the interval \pm 15 days surrounding the recommendation change. Untabulated findings indicate a strongly positive and significant correlation (0.37) between the two. However, the use of target prices would require a minimum of two adjustments: horizon and required return. Analyst reports provide little information on either dimension. Moreover, in our sample, there are many cases where analysts simultaneously upgrade (downgrade) and decrease (increase) target prices. Consequently, we use analyst recommendations as the indicator of analyst sentiment regarding a stock's valuation.
} 
a specific company. For instance, one observation would be a recommendation by Merrill Lynch regarding Intel. Therefore, there is no distinction in this sample between "analyst" recommendations and "brokerage firm" recommendations. Recommendations in the IBES database are coded as follows: $1=$ strong buy, $2=$ buy, $3=$ hold, $4=$ sell, $5=$ strong sell. It should be noted that the individual analyst responsible for the Merrill Lynch recommendation may change over time. If that is the case, and if the new Merrill Lynch analyst has a different recommendation, the result would be coded as a change in the Merrill Lynch recommendation. There are a total of 234,159 observations in the IBES file. Of these observations, 90,777 represent initializations in the data set. ${ }^{7}$

For each available broker-firm combination, daily recommendations are constructed from the IBES dataset. Recommendations can be upgraded, downgraded, affirmed (i.e., confirmation of prior recommendations), or remain unchanged. Unchanged recommendations, which represent the overwhelming majority of the observations, are constructed by "filling in the holes" between each of the 234,159 brokerage recommendations listed on the IBES database. That is, if there is no new information from a given brokerage on a given day for a given firm, the recommendation is assumed to remain unchanged.

Because the focus of this study is to determine how individual analysts respond to public information, we require a proxy for information that can be applied to a large sample of stocks without having to identify any particular information event. We choose price movements as a sufficient statistic for information events. The linkage that we presume between large stock price movements and information events is supported by evidence presented in Ryan and Taffler (2004) who find that $65 \%$ of price changes can be accounted for by the release of public information. For computational reasons, we select a subsample of firms for which there is some evidence of a significant news shock, i.e., a large price shock, during the sample period. ${ }^{8}$

We begin by determining for each firm in the recommendations database the beginning and end dates for which the firm is followed by at least one brokerage firm. Using these dates to define the time period for the firm, we construct a vector of returns for this period, beginning immediately before the start of the recommendations in the database. The vector is based on three-day compounded returns on the grounds that some information events may affect the market for more than one day. To illustrate how the vector of three-day returns is computed, consider a hypothetical firm, XYZ, Inc., which first appears in the recommendations database on July 11, 1996, and remains in the database until the end of 2000. The first three-day return for this firm is constructed from July 8 through July 10 , the second is from July 9 through July 11, until the last return from December 28

\footnotetext{
${ }^{7}$ Initializations may not actually represent when coverage by the particular broker began, but instead may only represent the first observation for the particular broker/firm combination in the data set.

${ }^{8}$ An alternative method of capturing news shocks is to use actual information releases, estimated from the unexpected components of the information released, and examine analysts' behavior around those dates. However, this requires a robust and feasible method of identifying important announcements ex ante, and measuring the unexpected components of those announcements ex post; this would obviously also entail measurement problems. In Section VII.B, we use a subsample of earnings announcements for which we can measure the unexpected component of the announcement.
} 
through December 30, 2000. The next step is to select an appropriate sample of extreme returns. Here an extreme return is defined as one in the top or bottom $1 \%$ tail of the distribution of all firms' three-day returns subject to two adjustments. First, each three-day return, $r_{i t}$, is netted against the contemporaneous Center for Research in Security Prices (CRSP) three-day value-weighted market return, $r_{m t}$. Second, to control for differences in sample firms' return volatilities along with possible changes in volatilities over time, each resulting net-of-market return, $r_{i t}-r_{m t}$, is scaled by the standard deviation of three-day net-of-market returns, $\sigma_{i t}\left(r_{i t}-r_{m t}\right)$, calculated using a sample of non-overlapping three-day netof-market returns prior to day $t$, i.e., those running from day -3 to day -249 relative to each day's return. A vector of market-adjusted returns, ADJRET3 ${ }_{i t}$, is computed simply as the ratio $\left[r_{i t}-r_{m t}\right] / \sigma_{i t}\left(r_{i t}-r_{m t}\right)$.

It is this sample of market-adjusted returns that is utilized to calculate upper and lower $1 \%$ tail cutoff points of the distribution of normalized three-day returns aggregated across all firms. By assumption, any firm exhibiting a stock return that falls outside these cutoffs has experienced a significant public information event in relation to both its own performance and the sample as a whole. When calculating the cutoff points, only non-overlapping returns are used. The resulting upper and lower $1 \%$ cutoff points for the ADJRET3 ${ }_{i t}$ distribution are -2.59 and 3.06 .

We select the final sample of extreme $1 \%$ return events for each firm by comparing the full vector of market-adjusted three-day returns to the cutoff points calculated from the overall sample. We avoid selecting overlapping returns as extreme events. That is, once a three-day period is flagged as an extreme return event, we do not select the next two (overlapping) three-day return events as extreme. For example, suppose the first three-day return for XYZ that meets one of these criteria is July 15, 1996. The three-day returns ending on July 16 and 17 would be deleted from the dataset and we would continue chronologically beginning on July 18 to search for the next return observation that meets the cutoff criteria.

This procedure, which is repeated for each firm in the IBES sample, results in 40,458 and 41,481 return events, respectively, in the lower and upper $1 \%$ tails. The larger number of return events in the upper $1 \%$ tail reflects the fact that lower tail events are associated with more overlapping returns that are eliminated when the samples are constructed. ${ }^{9}$

In our analysis, we measure the marginal effect of large price events on analyst recommendation levels. Consequently, we require a benchmark sample that includes periods in which no large price event occurs, in order to construct the unconditional probability of moving from one recommendation level to another.

\footnotetext{
${ }^{9}$ For a random sample of 500 large return events, we searched for news releases surrounding each event to understand better the potential source of the price movement. Not surprisingly, many large price movements occur close to announcements regarding earnings or preliminary earnings news. For some large return events, we could find no proximate announcement. We find little evidence that a single type of announcement is associated with our return events; we examine earnings announcements separately in Section VII. Overall, the random sample provides strong evidence that these return events are generally associated with "news." Furthermore, recommendation changes are five times more likely to occur after identifiable news events relative to unidentifiable ones, which suggests that our research design is biased against finding results.
} 
Thus, our sample period for these 81,939 return events extends from 20 days prior to the return event to 20 days after the return event, centered on day +1 relative to the last day of the $1 \%$ three-day return event. ${ }^{10}$ The additional days add cross-sectional variation in returns without which the power of our tests would be limited. That is, if we limit sample observations to include only large stock returns then the effect of returns on recommendation changes would be estimated with less precision. ${ }^{11}$

For our sample of firms with identified public information events, and for each day in the 41-day event window, we analyze how recommendation levels, and the probability of changing recommendations, are related to variables that are publicly available as of the previous day. As described in Section III.C, we use an ordered probit analysis of recommendation levels that allows for discreteness in individual analysts' recommendations and also yields a matrix of transition probabilities across recommendation levels.

\section{B. Univariate Analysis}

Table 1, Panels A and B, provides a variety of descriptive statistics for the sample. The first column in Panel A presents data for the full sample of IBES analysts' recommendations (All Firms), after filling in daily recommendations between discrete observations in the IBES database. The second column presents analogous data for the sample of recommendation changes on the day following a large return event (1\% Sample), where the large return event is defined as in Section IV.A. The last column presents recommendation change data for the 9,050,560 recommendation/days used in the probit analysis (Probit Sample). These are constructed using the 40 days surrounding the large return event in the $1 \%$ sample. The results in Panel A indicate that all samples are dominated by no changes. For example, among the probit sample, there are 9,000,482 no change observations. For this same sample, downgrades occur more frequently than upgrades $(24,581$ versus 17,610$)$ and, because recommendation changes are undefined for initializations, there are no initializations in the sample.

Panel B, which breaks down the recommendation changes by number of grades for the $1 \%$ and probit samples, indicates that among downgrades, recommendation changes of multiple grades are approximately twice as common as they are among upgrades. The fact that downgrades are more common than upgrades, particularly for multiple grade changes, is consistent with the positive bias in the level of recommendations mentioned earlier. In our sample, the average recommendation is 2.1 , which is approximately a buy. The fact that the level of recommendations already clusters at the optimistic end of the range provides

\footnotetext{
${ }^{10}$ Because large return events sometimes occur within 40 days of one another, our procedure of including observations for the probit analysis in the period \pm 20 days surrounding each identified public information event results in duplicate observations for certain firm/broker/date combinations. To avoid counting these dates multiple times, we remove duplicate entries, leaving a single observation for each firm/broker combination on any individual day. No large price event is excluded from the sample with this filter.

${ }^{11}$ We also estimated our probit analyses using all days in each sample quarter in which the large return event occurs. Untabulated results from these analyses yield similar inferences to those presented in the paper. In addition, our tests are robust to a $2 \%$ or $0.5 \%$ large return threshold and are not influenced by including only pre- or post-event returns in the analysis.
} 
TABLE 1

Recommendation Change Descriptive Statistics

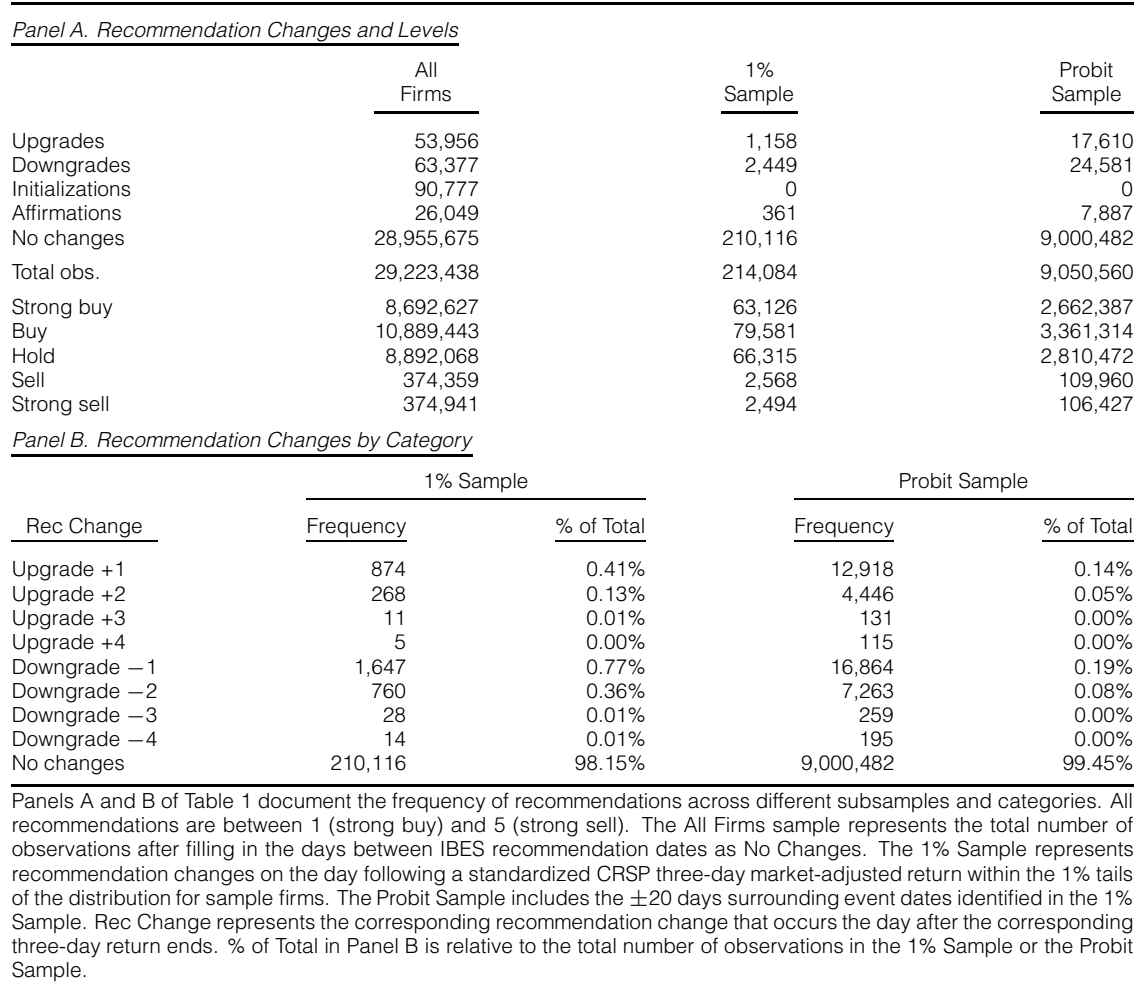

less room for future upgrades, particularly by more than one rating category. In the probit analysis, we estimate separate regressions for each recommendation level to take account of this congestion at the high end.

Panel B also demonstrates that analyst activity is much greater following large return events. For example, for the $1 \%$ sample, the frequency of upgrades is higher by a factor of 3 and the frequency of downgrades is higher by a factor of 4 when compared with the probit sample. The fact that there are relatively few changes in the recommendations but analysts are more likely to change recommendations following the large stock price events suggests that analysts believe that they have private information. This finding is inconsistent with H1. That is, analysts' recommendations appear to be based on value-to-price comparisons; a change in the market price may cause a change in their value-to-price comparison and hence a related change in their recommendations.

If analysts' recommendations are upwardly biased (Stickel (1995)), then the arrival of negative information may precipitate a greater response from analysts than good news. That is, there may be some circumstances in which accuracy is deemed more important than optimism, just as Hong and Kubik (2003) find that there are some analysts for whom optimism may be more important than accuracy. The findings in Table 1, which indicate a larger proportion of downgrades 
relative to upgrades, could be indicative of such an asymmetric response. The most direct way to assess the empirical validity of this conjecture is to split the sample based on the sign of the information shock. Table 2 partitions the $1 \%$ sample in Panel A and the probit sample in Panel B, based on the sign of the three-day standardized market-adjusted return event. It also includes summary statistics for the return. Table 2 indicates that the proportion of upgrades and downgrades (for all numbers of grades) associated with positive and negative return events differs dramatically. For example, Panel A reveals that whereas there are relatively equal numbers of upgrades and downgrades following positive returns (612 versus 567) there are more than three times the number of downgrades than upgrades following negative returns (1,882 versus 546). Panel B reveals a similar pattern of upgrades and downgrades in the 40-day window surrounding the large return events for the probit sample. The accompanying return information suggests that this asymmetrical analyst response cannot be explained by differences in return magnitudes preceding the response. The mean and median returns in the positive and negative return subsamples are not substantially different.

TABLE 2

Recommendation Change and Return Descriptive Statistics Based on Sign of Standardized Market-Adjusted Return

\begin{tabular}{|c|c|c|c|c|c|c|}
\hline $\begin{array}{l}\text { Return } \\
\text { Sign }\end{array}$ & Grade & $\begin{array}{l}\text { No. of } \\
\text { Obs. }\end{array}$ & $\begin{array}{l}\text { Mean } \\
\text { Return }\end{array}$ & $\begin{array}{l}\text { Median } \\
\text { Return }\end{array}$ & $\begin{array}{l}\text { Maximum } \\
\text { Return }\end{array}$ & $\begin{array}{c}\text { Minimum } \\
\text { Return }\end{array}$ \\
\hline \multicolumn{7}{|c|}{ Panel A. 1\% Sample } \\
\hline $\begin{array}{l}\text { Negative } \\
\text { Negative } \\
\text { Negative } \\
\text { Negative }\end{array}$ & $\begin{array}{l}\text { Upgrade } \\
\text { Downgrade } \\
\text { Affirm } \\
\text { No change }\end{array}$ & $\begin{array}{r}546 \\
1,882 \\
229 \\
111,292\end{array}$ & $\begin{array}{l}-3.60 \\
-4.42 \\
-3.79 \\
-3.25\end{array}$ & $\begin{array}{l}-3.19 \\
-3.73 \\
-3.17 \\
-2.97\end{array}$ & $\begin{array}{l}-2.59 \\
-2.59 \\
-2.59 \\
-2.58\end{array}$ & $\begin{array}{l}-10.45 \\
-19.86 \\
-11.65 \\
-19.86\end{array}$ \\
\hline $\begin{array}{l}\text { Positive } \\
\text { Positive } \\
\text { Positive } \\
\text { Positive }\end{array}$ & $\begin{array}{l}\text { Upgrade } \\
\text { Downgrade } \\
\text { Affirm } \\
\text { No change }\end{array}$ & $\begin{array}{r}612 \\
567 \\
132 \\
98,824\end{array}$ & $\begin{array}{l}4.23 \\
5.35 \\
4.05 \\
3.78\end{array}$ & $\begin{array}{l}3.74 \\
4.10 \\
3.69 \\
3.51\end{array}$ & $\begin{array}{l}16.66 \\
43.61 \\
11.52 \\
76.98\end{array}$ & $\begin{array}{l}3.06 \\
3.07 \\
3.09 \\
3.06\end{array}$ \\
\hline \multicolumn{6}{|c|}{ Panel B. Probit Sample } & \\
\hline $\begin{array}{l}\text { Negative } \\
\text { Negative } \\
\text { Negative } \\
\text { Negative }\end{array}$ & $\begin{array}{l}\text { Upgrade } \\
\text { Downgrade } \\
\text { Affirm } \\
\text { No change }\end{array}$ & $\begin{array}{r}8,311 \\
16,252 \\
4,208 \\
4,794,823\end{array}$ & $\begin{array}{l}-0.44 \\
-1.18 \\
-0.50 \\
-0.23\end{array}$ & $\begin{array}{l}-0.25 \\
-0.67 \\
-0.29 \\
-0.18\end{array}$ & $\begin{array}{r}13.83 \\
40.42 \\
7.24 \\
41.93\end{array}$ & $\begin{array}{l}-13.92 \\
-19.86 \\
-12.19 \\
-23.14\end{array}$ \\
\hline $\begin{array}{l}\text { Positive } \\
\text { Positive } \\
\text { Positive } \\
\text { Positive }\end{array}$ & $\begin{array}{l}\text { Upgrade } \\
\text { Downgrade } \\
\text { Affirm } \\
\text { No change }\end{array}$ & $\begin{array}{r}9,299 \\
8,329 \\
3,679 \\
4,205,659\end{array}$ & $\begin{array}{l}0.70 \\
0.67 \\
0.34 \\
0.21\end{array}$ & $\begin{array}{l}0.38 \\
0.17 \\
0.11 \\
0.03\end{array}$ & $\begin{array}{r}20.45 \\
43.61 \\
27.39 \\
175.10\end{array}$ & $\begin{array}{r}-11.16 \\
-18.19 \\
-6.99 \\
-23.04\end{array}$ \\
\hline Total obs. & & $9,050,560$ & & & & \\
\hline
\end{tabular}

Panel A of Table 2 documents standardized CRSP three-day market-adjusted return descriptive statistics for firms within the $1 \%$ tails of the return distribution for sample firms. Standardized returns are calculated utilizing three-day marketadjusted returns scaled by the standard deviation of three-day market-adjusted returns over day -3 to -249 . The Return Sign is designated as positive (negative) if the preceding three-day return was greater than or equal to (less than) zero. Grade represents the recommendation change occurring on the day following the final day of the standardized threeday return. Panel $\mathrm{B}$ documents the corresponding statistics in Panel A for the Probit Sample, which includes \pm 20 days surrounding event dates identified in the $1 \%$ Sample.

In Table 3, we present a transition matrix of the probability of moving from one recommendation level to another, for the $1 \%$ sample and the probit samples. This analysis extends the analysis in Tables 1 and 2 to include information about the analysts' initial recommendation level. Panels A and B present evidence for negative and positive return shocks. Using the probabilities in each transition matrix, we compute and report an average daily recommendation change, which 
is calculated by multiplying the indicated probability by the corresponding recommendation change and summing across all possible recommendation change categories where upgrades (downgrades) are recorded as negative (positive) numbers.

TABLE 3

Recommendation Change Probability Matrices

\begin{tabular}{|c|c|c|c|c|c|c|c|c|c|c|c|}
\hline & \multicolumn{5}{|c|}{$\begin{array}{l}\text { 1\% Sample Transition Matrix } \\
\text { New Recommendation }\end{array}$} & & \multicolumn{5}{|c|}{$\begin{array}{l}\text { Probit Sample Transition Matrix } \\
\text { New Recommendation }\end{array}$} \\
\hline \multicolumn{12}{|c|}{ Panel A. Negative Returns } \\
\hline$\underline{L R E C}$ & 1 & 2 & 3 & 4 & 5 & $\underline{L R E C}$ & 1 & 2 & 3 & 4 & 5 \\
\hline 1 & $97.17 \%$ & $1.34 \%$ & $1.44 \%$ & $0.03 \%$ & $0.02 \%$ & 1 & $99.39 \%$ & $0.31 \%$ & $0.30 \%$ & $0.01 \%$ & $0.01 \%$ \\
\hline 2 & $0.55 \%$ & $97.54 \%$ & $1.82 \%$ & $0.06 \%$ & $0.02 \%$ & 2 & $0.16 \%$ & $99.48 \%$ & $0.35 \%$ & $0.01 \%$ & $0.00 \%$ \\
\hline 3 & $0.30 \%$ & $0.50 \%$ & $98.91 \%$ & $0.16 \%$ & $0.14 \%$ & 3 & $0.12 \%$ & $0.20 \%$ & $99.62 \%$ & $0.03 \%$ & $0.03 \%$ \\
\hline 4 & $0.07 \%$ & $0.07 \%$ & $1.04 \%$ & $98.81 \%$ & $0.00 \%$ & 4 & $0.04 \%$ & $0.13 \%$ & $0.47 \%$ & $99.32 \%$ & $0.04 \%$ \\
\hline 5 & $0.14 \%$ & $0.22 \%$ & $0.87 \%$ & $0.07 \%$ & $98.70 \%$ & 5 & $0.09 \%$ & $0.07 \%$ & $0.52 \%$ & $0.04 \%$ & $99.28 \%$ \\
\hline \multicolumn{6}{|c|}{$\begin{array}{l}\text { Avg. recommendation change } \\
\text { Panel B. Positive Returns }\end{array}$} & \multicolumn{4}{|c|}{ Avg. recommendation change } & 0.002 & \\
\hline LREC & 1 & 2 & 3 & 4 & 5 & LREC & 1 & 2 & 3 & 4 & 5 \\
\hline 1 & $99.02 \%$ & $0.39 \%$ & $0.55 \%$ & $0.01 \%$ & $0.03 \%$ & 1 & $99.63 \%$ & $0.19 \%$ & $0.16 \%$ & $0.00 \%$ & $0.01 \%$ \\
\hline 2 & $0.46 \%$ & $98.89 \%$ & $0.61 \%$ & $0.02 \%$ & $0.01 \%$ & 2 & $0.19 \%$ & $99.60 \%$ & $0.21 \%$ & $0.00 \%$ & $0.00 \%$ \\
\hline 3 & $0.40 \%$ & $0.81 \%$ & $98.65 \%$ & $0.05 \%$ & $0.09 \%$ & 3 & $0.15 \%$ & $0.26 \%$ & $99.55 \%$ & $0.02 \%$ & $0.02 \%$ \\
\hline 4 & $0.24 \%$ & $0.57 \%$ & $1.62 \%$ & $97.58 \%$ & $0.00 \%$ & 4 & $0.06 \%$ & $0.13 \%$ & $0.58 \%$ & $99.21 \%$ & $0.02 \%$ \\
\hline 5 & $0.27 \%$ & $0.36 \%$ & $1.69 \%$ & $0.09 \%$ & $97.59 \%$ & 5 & $0.12 \%$ & $0.08 \%$ & $0.60 \%$ & $0.03 \%$ & $99.16 \%$ \\
\hline \multicolumn{6}{|c|}{ Avg. recommendation change } & \multicolumn{4}{|c|}{ Avg. recommendation change } & 0.000 & \\
\hline
\end{tabular}

Table 3 presents frequency percentages of movements in recommendations within both the $1 \%$ and Probit Samples. LREC is the recommendation level on the day prior to the recommendation change (i.e., the lagged recommendation) where 1 represents strong buy and 5 represents strong sell. The 1\% and Probit Sample Transition Matrices are calculated by dividing the frequencies in each cell by the summation of all the frequencies in a given row (i.e., the probability for $L R E C=1$ and New Recommendation $=1$ is calculated by taking the number of times this occurs in the sample and dividing by the total number of times $\angle R E C=1$ ). Average Recommendation changes are calculated by multiplying the indicated probability by the corresponding recommendation change and summing across all possible recommendation change categories where upgrades (downgrades) are recorded as negative (positive) numbers. The changes are weighted by the total number of observations in their corresponding $L R E C$ level relative to the total number of observations for the respective sample.

Comparing the two matrices in the $1 \%$ sample (the two left-hand side matrices in Table 3), the asymmetry in analyst response is apparent in this univariate analysis. The average daily recommendation change following a large negative return is 0.016 , indicating a downgrade. Following a large positive return, the average daily recommendation change is $0.000 .{ }^{12}$ This difference in analyst response across positive and negative returns is consistent with the evidence presented in Boni and Womack (2006) in this issue and suggests that the multivariate analysis should be conducted separately for positive and negative return observations.

Comparison of the two right-hand side matrices in Table 3 that relate to the probit sample shows virtually no asymmetry and, indeed, little indication of any recommendation change by analysts when the sample is extended to include days other than those immediately following the large return event. This is not surprising as it indicates that the unconditional probability of an analyst recommendation change is essentially zero.

\footnotetext{
${ }^{12}$ We thank Ivo Welch (the referee) for suggesting the transition matrix analysis.
} 


\section{Multivariate Analysis}

Recommendations are coded into five discrete categories. This feature of the data suggests the use of ordered probit analysis, with recommendation levels as the dependent variable and stock price movements as the key independent variable. Because recommendation levels are presumably affected by other variables, we include additional independent variables as controls.

In particular, we seek to explain recommendations made by specific analysts in the 40 trading days surrounding the large return event, i.e., in the $1 \%$ upper and lower return tails. The values of recommendation levels, $R E C$, are limited dependent variables, in that the true recommendation levels, $R E C^{*}$, are unobservable. Under the assumption of a standardized unit normal distributed error term, i.e., $\varepsilon \sim N(0,1)$, ordered probit can be used to estimate the underlying latent relation,

$$
R E C^{*}=\beta^{\prime} X+\varepsilon .
$$

We use maximum likelihood estimation to estimate the vector of model parameters, $\beta$, which represent the marginal effects of changes in regressors, $X$, on the probabilities, $\operatorname{Prob}(R E C=k), k=1,2,3,4$, and 5. In addition, cutoff points $\mu_{\kappa}$, are imputed where

$$
\begin{aligned}
R E C & =1 \text { if } R E C^{*} \leq \mu_{0} \\
& =2 \text { if } \mu_{0}<R E C^{*} \leq \mu_{1} \\
& =3 \text { if } \mu_{1}<R E C^{*} \leq \mu_{2} \\
& =4 \text { if } \mu_{2}<R E C^{*} \leq \mu_{3} \\
& =5 \text { if } \mu_{3}<R E C^{*} .
\end{aligned}
$$

Note that except for the endpoints, $k=1$ and $k=5$, the signs of the changes in probabilities as a function of changes in the regressors are ambiguous. However, partial derivatives for $\operatorname{Prob}(R E C=k)$ with respect to each of the regressors evaluated at sample means can be computed using estimated model parameters (see Green (1997), pp. 926-931, for a more complete description of ordered probit). For example, for a particular continuous variable, $X_{j}$, we can compute the change in $\operatorname{Prob}(R E C=k)$ from $X_{j}=\bar{X}_{j}+\sigma_{j}$ to $X_{j}=\bar{X}_{j}-\sigma_{j}$, holding all other variables constant at their sample means. For a particular discrete $0 / 1$ variable, $X_{j}$, we can compute the difference in $\operatorname{Prob}(R E C=k)$ for $X_{j}=1$ and $X_{j}=0$, again holding all other variables constant at their sample means. At a practical level, because our sample is dominated by no change observations, the computed changes are all going to be relatively small. In unreported analyses, we note that these probability ratios vary monotonically across the recommendation level categories, therefore we can interpret the sign of the coefficient as having the same influence on the dependent variable as in an ordinary regression.

The ordered probit model used here is given by (3). Observations are timeindexed from day -20 to day +20 , where day 0 is the day following the end of the extreme $1 \%$ three-day return event that caused a firm to be included in the sample. The recommendation level on day $t$, for firm $i$ by brokerage firm $j$, is denoted by 
the variable $R E C_{i j t}$. We estimate the ordered probit separately for each initial recommendation level.

$$
\begin{aligned}
& R E C_{i j t}=\alpha_{0}+\alpha_{1} A D J R E T 3_{i t}+\alpha_{2} N_{E G R E T_{i t}} \\
& +\alpha_{3} \text { NEGRET }_{i j} * \text { ADJRET3 }_{i t}+\alpha_{4} \text { ADJRET10 }_{i t}+\alpha_{5} \text { AFIL }_{i j} \\
& +\alpha_{6} \text { AFIL }_{i j} * \text { ADJRET3 }_{i t}+\alpha_{7} \text { AFIL }_{i j} * \text { ADJRET1O }_{i t} \\
& +\alpha_{8} \text { LMNREC }_{i t}+\alpha_{9} \text { LMNREC1O }_{i t}+\alpha_{10} \text { NUMREC }_{i t} \\
& +\alpha_{11} \text { LPERC }_{i t}+\alpha_{12} \text { LPERC10 }_{i t}+\alpha_{13} A G E_{i} \\
& +\alpha_{14} M V E_{i t}+\alpha_{15} P R I C E_{i t}+\alpha_{16} S M A L L_{i t} \\
& +\alpha_{17} \text { SMALL }_{i} * \operatorname{ADJRET3}_{i t}+\varepsilon_{i j t} \text {, where }
\end{aligned}
$$

$R E C_{i j t} \quad=\quad$ recommendation level for firm $i$ by analyst $j$ on day $t, t=$ $-20, \ldots,+20$

ADJRET3 $_{i t}=$ standardized market-adjusted return for firm $i$ for the three days preceding analyst $j$ 's recommendation change at day $t$;

NEGRET $_{i t}=$ one if ADJRET3 ${ }_{i t}<0$ and zero otherwise;

$A D J R E T 10$ it $=$ standardized market-adjusted return for firm $i$ for the 10 days commencing 13 days before and ending four days before analyst $j$ 's recommendation change at day $t$;

$A F I L_{i j} \quad=$ one if analyst $j$ 's firm has an investment banking relationship with firm $i$ as of day $t$, and zero otherwise;

$L M N R E C 3_{i t}=$ mean recommendation change for firm $i$ for the three days preceding analyst $j$ 's recommendation change at day $t$; calculated as mean recommendation level at day $t-1$ less mean recommendation level at day $t-4$.

LMNREC10 ${ }_{i t}=$ mean recommendation change for firm $i$ for the 10 days commencing 13 days before and ending four days before analyst $j$ 's recommendation change at day $t$; calculated as mean recommendation level at day $t-4$ less mean recommendation level at day $t-13$.

$N U M R E C_{i t}=$ number of analysts following firm $i$ at time $t$;

${ }_{L P E R C} 3_{i t}=$ percentage of analysts following firm $i$ at time $t$ that change their recommendation during the three days preceding analyst $j$ 's recommendation change at day $t$;

$\operatorname{LPERC1O}_{i t}=$ percentage of analysts following firm $i$ at time $t$ that change their recommendation during the 10 days commencing 13 days before and ending four days before analyst $j$ 's recommendation change at day $t$;

$A G E_{i} \quad=\quad$ number of years between current year and year firm $i$ first appears on CRSP;

$M V E_{i t} \quad=$ equity market value (in thousands) on day $t$ for firm $i$;

PRICE $_{i t} \quad=$ stock price for firm $i$ on day $t$; and 
$S M A L L_{i} \quad=\quad$ one if firm is in the smallest equity market value decile for all sample observations within the quarter in which day $t$ falls, and zero otherwise.

The primary empirical question of this study is whether analysts exhibit a greater tendency to change their recommendations in response to major news, with large stock price events serving as our proxy for news shocks. Our purpose for expanding the event window to \pm 20 days surrounding the end of the $1 \%$ tail three-day return interval is to estimate more accurately the probability of moving from one recommendation level to another by including "non-event" days surrounding the large return event days. ${ }^{13}$ By construction, because the return interval associated with ADJRET3 ends before $R E C_{i j t}$ is observed, ADJRET3 should not be affected by $R E C$. However, to allow for the possibility that events prior to the immediate three days could affect the analyst recommendation level, we include an additional explanatory variable, ADJRET10, which extends the return event interval back an additional 10 days.

To determine whether investment banking relationships can possibly affect the analyst recommendation level, we include $A F I L$, an indicator variable that equals one if the analyst's firm has an investment banking affiliation and zero otherwise. ${ }^{14}$ To allow for the possibility that affiliation affects the probability of the analyst changing his recommendation in response to stock price movements, we also include the interaction of AFIL with ADJRET3 and ADJRET10. Because the probability of an analyst responding to large returns may be greater for small firms, we also allow both the intercept and the return response to vary with the market capitalization of the firm by including an indicator variable, SMALL, if a firm is in the smallest size decile, as well as a variable interacting SMALL with ADJRET3.

It is possible that analysts' recommendations reflect not just the return event but also actions taken by their peers following the same stock during the same three-day period. The tendency of analysts to alter their recommendations in response to recent actions taken by their peers would occur if analysts have a tendency to "herd" (e.g., Welch (2000)). To test for this, we include LMNREC3 and $L P E R C 3$, which are the mean recommendation change for firm $i$ and percentage of analysts following firm $i$ that change their forecasts in the three days preceding analyst $j$ 's recommendation change on day $t$. As with the return variables, to allow for the possibility that events prior to the immediate three days could affect the recommendation level, we include additional explanatory variables, LMNREC10 and LPERC10, which extends the event interval back an additional 10 days.

We include several variables that capture the amount of public information, interest, or following that a firm might have. First, we include NUMREC, the

\footnotetext{
${ }^{13}$ Note we may also be including in our non-event period large return event days that were excluded in the construction of the sample to avoid overlapping returns. If return events are important in determining analysts' recommendation changes, this will bias against our finding a significant relation between the return events and recommendation changes.

${ }^{14}$ To determine whether an analyst's firm had an investment banking relationship with the firm for which he supplied a recommendation, we matched firms on CUSIP common to the IBES and Securities Data Corporation (SDC) datasets. We assume an investment banking relationship exists if the SDC dataset indicates there were any debt or equity offerings or merger and acquisition activity sponsored by the analyst's firm any time during the IBES sample period.
} 
number of analysts following the firm. Other variables that might capture the amount of publicly available information on the firm include $M V E$ and AGE. Finally, we include, PRICE, the firm's stock price on the event day, as an additional control. This variable is typically considered as a proxy for liquidity, and hence may control for the incentive to collect (and profit from) private information about a firm.

We estimate equation (3) by pooling observations across $i=1, \ldots, I$ firms and $j=1, \ldots, J$ analysts during the \pm 20 day window surrounding the large stock return event. In addition, as noted above, we estimate equation (3) separately for each initial recommendation level. In our discussion below, we refer to the initial or starting recommendation level as $L R E C$, to distinguish it from the ending recommendation level, $R E C$.

\section{Data}

Table 4, Panels A and B, presents sample summary statistics for all variables used in the probit analysis. The mean firm in our sample is 16 years old, has a price of $\$ 36$, and has approximately $\$ 7.1$ billion of equity outstanding. ${ }^{15}$ On average, sample firms are not affiliated with the analyst making the recommendation, with only $3 \%$ of sample firms having an affiliation with the brokerage houses employing the analyst in our sample. On average, nine analysts cover each firm in our sample, and in the last three (10) days, 1\% (5\%) of other analysts covering the firm have changed their recommendation levels. The mean recommendation changes (across all analysts covering the firm) in the three- and 10-day periods prior to each analyst's recommendation change, LMNREC3 and LMNREC10, are both near zero, reflecting the fact that analysts rarely change recommendations.

Panel B, which presents summary statistics for the return variables based on the sign of the three-day return event, indicates the mean standardized threeday return preceding a recommendation change, ADJRET3, is similar in absolute magnitude for both negative and positive return subsamples, -0.93 and 1.01, respectively. The mean standardized 10-day return preceding that three-day return, ADJRET10, indicates there is modest evidence of price reversals for the positive return events, -0.11 , and a virtually flat price movement for negative return events, -0.02 . Since these two return measures share a common price (i.e., the ending price used to calculate ADJRET10 is also the beginning price for ADJRET3), this effect may be attributable to bid-ask bounce (see, e.g., Blume and Stambaugh (1983)).

\section{Probit Results}

Table 5 presents the ordered probit summary statistics for equation (3). Panel A reports the findings for the overall sample; Panel B reports the coefficients on the three-day returns variables for each of the initial recommendation levels. Panel A reports mean coefficient estimates from five probit regressions corresponding to the initial recommendation levels, along with significance tests based

\footnotetext{
${ }^{15}$ Median (Q1) NYSE/AMEX/NASDAQ decile rankings for sample firms is 8 (6) indicating that the sample is primarily composed of large, well-established firms.
} 
TABLE 4

Probit Sample Summary Statistics

\begin{tabular}{|c|c|c|c|}
\hline \multicolumn{4}{|c|}{ Panel A. Descriptive Statistics } \\
\hline Variable & Mean & Median & Std. Dev. \\
\hline ADJRET3 & -0.03 & -0.08 & 1.37 \\
\hline ADJRET10 & -0.06 & -0.12 & 1.45 \\
\hline AFFIL & 0.03 & 0.00 & 15.72 \\
\hline LMNREC3 & 0.00 & 0.00 & 0.08 \\
\hline LMNREC10 & 0.01 & 0.00 & 0.15 \\
\hline NUMREC & 9.48 & 8.00 & 7.05 \\
\hline LPERC3 & 0.01 & 0.00 & 0.07 \\
\hline LPERC10 & 0.05 & 0.00 & 0.13 \\
\hline$A G E$ & 16.04 & 12.00 & 12.23 \\
\hline MVE (000) & $7,065,174$ & $1,322,184$ & $19,610,511$ \\
\hline PRICE & 35.84 & 28.00 & 361.90 \\
\hline \multicolumn{4}{|c|}{ Panel B. Average Returns by Return Sign } \\
\hline Return Sign & Variable & Mean & Median \\
\hline Negative & ADJRET3 & -0.93 & -0.69 \\
\hline Negative & ADJRET10 & -0.02 & -0.09 \\
\hline Positive & ADJRET3 & 1.01 & 0.71 \\
\hline Positive & ADJRET10 & -0.11 & -0.14 \\
\hline
\end{tabular}

In Table 4, the Probit Sample represents recommendation changes following three-day standardized returns within the \pm 20 days surrounding observations in the $1 \%$ return tails of the distribution for sample firms. Panel $A$ presents mean, median, and standard deviations of variables utilized in the ordered probit estimation presented in Table 5. Panel B documents descriptive statistics for our return variables, ADJRET3 and ADJRET10, based on the sign of ADJRET3.

upon the summation of individual $\chi^{2}$ statistics. ${ }^{16}$ Because upgrades (downgrades) are not possible when the initial recommendation is one or five (i.e., LREC1 or $L R E C 5)$, we also report average coefficients for only interior initial recommendations (i.e., LREC2, LREC3, and LREC4) in the last two columns of Table 5.

Turning to the key variable of interest, ADJRET3, the findings in Table 5 indicate that analysts respond to large price shocks, rejecting the $\mathrm{H} 1$ prediction that because analysts do not believe that they have private information, they will not respond to public information. That is, in addition to the evidence in Table 2 , which suggests that analysts respond more frequently following large return events, the evidence in Table 5 implies that analysts respond systematically to both positive and negative return events - analysts are not simply offsetting each other's recommendation changes. In particular, the coefficient on positive threeday return events, ADJRET3, 0.012, is significant, indicating that analysts tend to downgrade following a large positive return event. In contrast to the effect of positive return events, the total coefficient on negative three-day return events $(A D J R E T 3+A D J R E T 3 * N E G R E T),-0.078$, is significant and substantially larger in magnitude than the effect of positive return events. That is, the findings indicate that analysts systematically respond much more strongly to large negative price shocks. This asymmetry in the analyst response to large price shocks is evidence supportive of the $\mathrm{H} 3$ prediction that analysts believe that they possess private information but their recommendations are "sticky" downward. In addition, these results hold even after removing consideration of the extreme recommendation levels, $L R E C 1$ and $L R E C 5$; the total coefficient on negative three-day return events $(A D J R E T 3+$ ADJRET3 $*$ NEGRET $),-0.046$, is significant and substan-

\footnotetext{
${ }^{16}$ All parameter estimates and significance tests are weighted by the number of observations corresponding to each lagged recommendation level (LREC). Throughout the paper, we use a $5 \%$ criterion for assessing statistical significance.
} 
tially larger in magnitude than the effect of positive return events, -0.017 . We examine the economic significance of these results in Table 6.

TABLE 5

Ordered Probit Analysis of the Likelihood of Recommendation Change

$\underline{\text { Panel A. Coefficient Summaries }}$

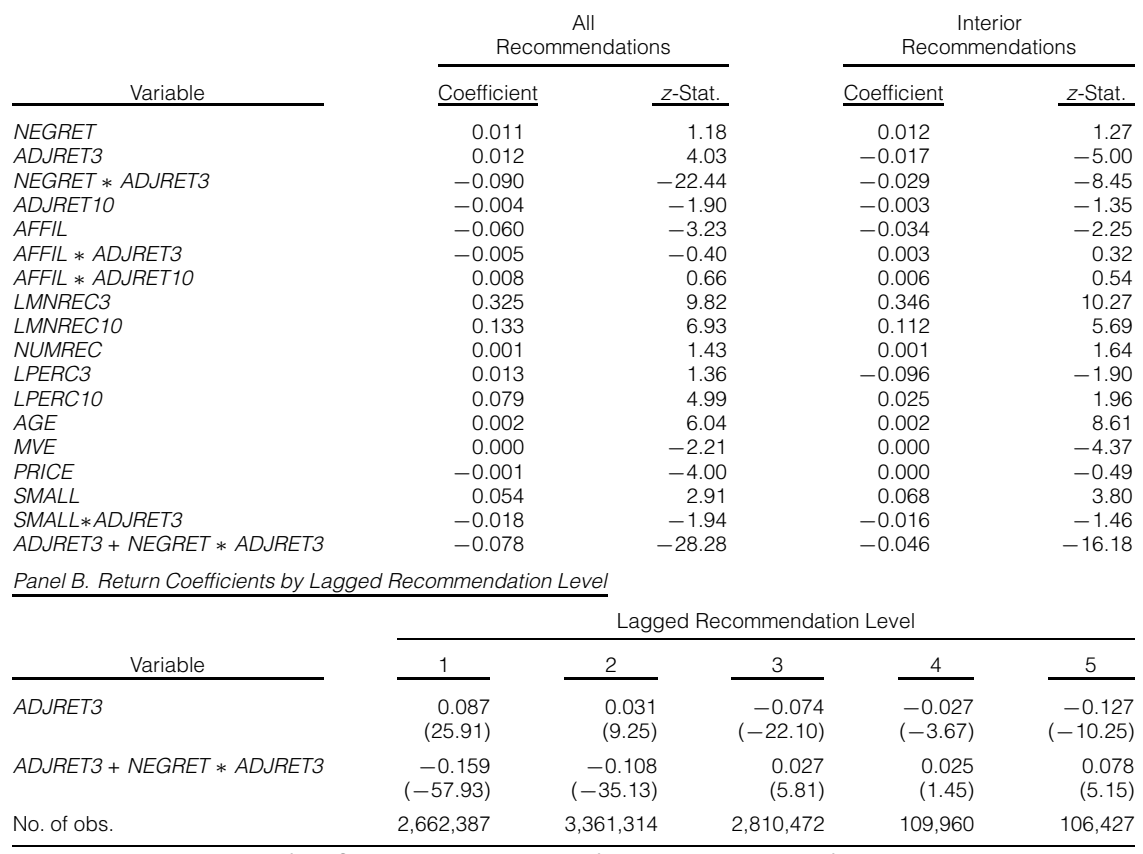

Table 5 presents the results of the Ordered Probit regression of recommendation levels following three-day standardized returns within the \pm 20 days surrounding returns in the $1 \%$ Sample defined in Table 1 . We estimate five separate regressions corresponding to each lagged recommendation level and then calculate weighted average coefficient and $z$-statistic estimates utilizing the number of observations in each regression as the weights. The All Recommendations columns utilize all lagged recommendation levels to derive coefficient and significance estimates, whereas the Interior Recommendations columns only utilize lagged recommendation levels 2, 3, and 4. Reported results all correspond to the probability of being in the worse recommendation categories (i.e., strong sell, sell, and hold). z-statistics are in parentheses.

The findings in Panel B of Table 5 indicate that the asymmetry for the threeday returns variables is largely driven by the observations relating to LREC1 and LREC2, which comprise two-thirds of the sample. Specifically, the total coefficients on negative three-day return events $(A D J R E T 3+A D J R E T 3 * N E G R E T)$ for $L R E C 1$ and $L R E C 2,-0.159$ and -0.108 , are significant and substantially larger in magnitude than the effect of positive return events, 0.087 and 0.031 . For the remaining third of the sample, the coefficients on positive return events are negative, and the coefficients on negative return events are positive, indicating a propensity to upgrade in all cases. However, the differences in the magnitude are substantially smaller than for LREC1 and LREC2.

Table 5 also reveals that the coefficient on $A F I L$ is generally negative and statistically significant, for the full sample and the subsample of interior recommendation levels. The negative sign suggests that the probability of moving to a lower (and therefore better) recommendation level is greater if there is a historical 
investment banking relationship between the brokerage firm making the recommendation and the firm for which the recommendation is issued. The coefficient on market capitalization, $M V E$, is negative, suggesting that analysts give better recommendations to larger firms. For the smallest firms in the sample, this tendency is exacerbated: the coefficient on SMALL is positive and significant in both samples, indicating that analysts have a tendency to give even lower recommendations to the firms in the smallest market value decile. Table 5 also indicates that the coefficients on LMNREC3 and LMNREC10 are positive and significant. This is consistent with the probability of an upgrade (downgrade) being higher if other analysts following the same firm upgraded (downgraded) the stock in the prior three- and 10-day periods. This finding also provides some added support for the notion of herding among analysts studied by Welch (2000), among others. Related to this, we see some evidence in the full sample that the recommendation level of an individual analyst is affected by the proportion of other analysts who change their recommendation. In particular, the coefficient on LPERC10 is significantly positive, indicating a greater propensity to downgrade if other analysts have changed their recommendation on the stock. Looking at interior recommendation levels only, the coefficient on LPERC10 remains positive and marginally significant.

TABLE 6

Probit Sample Large Return Transition Matrix

\begin{tabular}{|c|c|c|c|c|c|}
\hline Panel A. Negative Returns & \multicolumn{5}{|c|}{ New Recommendation } \\
\hline LREC & 1 & 2 & 3 & 4 & 5 \\
\hline $\begin{array}{l}1 \\
2 \\
3 \\
4 \\
5\end{array}$ & $\begin{array}{r}98.98 \% \\
0.09 \% \\
0.13 \% \\
0.04 \% \\
0.15 \%\end{array}$ & $\begin{array}{r}0.50 \% \\
99.41 \% \\
0.23 \% \\
0.12 \% \\
0.10 \%\end{array}$ & $\begin{array}{r}0.49 \% \\
0.49 \% \\
99.60 \% \\
0.50 \% \\
0.72 \%\end{array}$ & $\begin{array}{r}0.01 \% \\
0.01 \% \\
0.02 \% \\
99.30 \% \\
0.05 \%\end{array}$ & $\begin{array}{r}0.02 \% \\
0.01 \% \\
0.03 \% \\
0.03 \% \\
99.00 \%\end{array}$ \\
\hline $\begin{array}{l}\text { Avg. recommendation change } \\
\text { Panel B. Positive Returns }\end{array}$ & & 0.005 & & & \\
\hline LREC & 1 & 2 & 3 & 4 & 5 \\
\hline $\begin{array}{l}1 \\
2 \\
3 \\
4 \\
5\end{array}$ & $\begin{array}{r}99.33 \% \\
0.16 \% \\
0.23 \% \\
0.06 \% \\
0.25 \%\end{array}$ & $\begin{array}{r}0.34 \% \\
99.55 \% \\
0.38 \% \\
0.17 \% \\
0.16 \%\end{array}$ & $\begin{array}{r}0.31 \% \\
0.29 \% \\
99.38 \% \\
0.67 \% \\
1.07 \%\end{array}$ & $\begin{array}{r}0.01 \% \\
0.01 \% \\
0.01 \% \\
99.08 \% \\
0.07 \%\end{array}$ & $\begin{array}{r}0.01 \% \\
0.00 \% \\
0.01 \% \\
0.02 \% \\
98.46 \%\end{array}$ \\
\hline Avg. recommendation change & & 0.000 & & & \\
\hline
\end{tabular}

Table 6 provides transition matrices derived from the coefficients presented in Table 5 holding all continuous (indicator) variables at their means $(0)$ and setting the three-day adjusted return variables equal to their $1 \%$ cutoff points (i.e., -2.59 and 3.06 for the negative and positive return subsamples, respectively). Average Recommendation changes are calculated by multiplying the indicated probability by the corresponding recommendation change and summing across all possible recommendation change categories where upgrades (downgrades) are recorded as negative (positive) numbers. The changes are weighted by the total number of observations in their corresponding $L R E C$ level relative to the total number of observations for the respective sample. $L R E C$ is the recommendation level on the day prior to the recommendation change (i.e., the lagged recommendation) where 1 represents strong buy and 5 represents strong sell.

To assess the economic significance of the probit results on the ADJRET3 coefficients, we calculate transition matrices utilizing the probit model specification in Table 5 holding all continuous (indicator) variables at their means $(0)$ and setting the three-day adjusted return variables equal to their $1 \%$ cutoff points (i.e., -2.59 and 3.06 for the negative and positive return subsamples, respec- 
tively). As in Table 3, average recommendation changes are calculated by multiplying the indicated probability by the corresponding recommendation change and summing across all possible recommendation change categories where upgrades (downgrades) are recorded as negative (positive) numbers. The results, which are presented in Table 6 , also indicate that the effect of a negative return event is economically significant - that is, conditional on a negative return event, the expected daily recommendation change is 0.005 . This is in marked contrast to the evidence for positive returns events - in particular, the conditional expected daily recommendation change in Panel B of Table 6 of $0.000 .{ }^{17}$ Thus, using the probit model to control for the effects of other factors in addition to the three-day return yields the same inferences regarding asymmetry for negative and positive return events as seen in the unconditional results in Table 3. In addition, Table 6 confirms the inferences drawn from the estimated coefficients in the probit analysis: analysts tend to downgrade following a negative return event, while there is no apparent incremental response to a positive return event.

\section{Discussion of Results}

The most striking result to emerge from the probit analysis is the asymmetry between the results for positive and negative returns. For the positive return sample, we see a relatively small positive coefficient on positive price shocks in the full sample, and this coefficient changes sign in the subsample of interior recommendation levels. In terms of economic significance, we see very little change in the expected recommendation level when we condition on a positive return shock. These results suggest that, conditional on a positive return event, analysts react as if prices and fundamental values move in concert-the average investment rating of the companies is largely unchanged. More specifically, following large positive returns, the probability of upgrades and downgrades in Table 6 is about equal. Following price increases, analysts do not simply follow up with upgrades, as they would if they consistently believed the market underreacts, nor do they behave as if the market systematically overreacts. This finding is potentially consistent with any of the three hypotheses.

The picture for large negative changes is markedly different. The expected recommendation change following large stock price drops is a downgrade. In addition, the $z$-statistics for coefficients of ADJRET3 are large for the sample in general, large for the interior recommendation levels, and are even more significant for small firms. This asymmetry is inconsistent with both of the first two hypotheses. Furthermore, if recommendations are interpreted as comparisons of fundamental value with price, these results appear to imply that analysts believe that the market underreacts on average to bad news, but not good news.

\footnotetext{
${ }^{17}$ The average daily recommendation change of 0.005 following large negative return events implies that on average, one out of 200 analysts will downgrade one recommendation level on a daily basis. It is also similar in magnitude to that associated with a subsample of observations relating to earnings announcements (see Section VII.B). In particular, we estimated the ordered probits permitting the coefficients on ADJRET3 and ADJRET3 * NEGRET to differ based on whether any day in the three-day return window was within \pm 1 day of an earnings announcement. Untabulated findings indicate that none of the incremental earnings-related coefficients differs significantly from zero.
} 
In Section VII, we test whether prices in this sample behave in a manner consistent with underreaction, and find no evidence of it. Thus, it appears that forces other than direct price-to-value comparisons have an impact on analyst recommendations. H3 offers one interpretation that is consistent with the data, namely that business pressure causes analysts to trade off accuracy and optimism. Given this pressure, negative stock price movements serve as catalysts that allow analysts to downgrade their recommendations without necessarily eliminating the optimistic bias.

Note that our results are also consistent with the literature on information cascades. Suppose that analysts are under pressure to rate companies highly and not to downgrade for fear of insulting potential clients. This effect, furthermore, may well extend beyond clients with which a particular investment bank is currently, or has been historically, affiliated; firms may be worried about future investment banking business, or access to management (in a pre-Reg FD period) to provide information with which to form estimates of private value. Given this pressure, analysts need unambiguous external cues (with which management of potential clients cannot quarrel) to help them cut ratings. According to this interpretation, analysts recognize that their recommendations are too optimistic. The arrival of bad news makes it possible to downgrade the company without fear of retribution. This interpretation is consistent with predicted behavior in models examining informational cascades (Bikhchandani, Hirshleifer, and Welch (1992)), as well as the evidence in Welch (2000) that suggests that consensus herding is more prevalent in up-markets. It is also consistent with the empirical evidence presented in Lin, McNichols, and O'Brien (2004), who find that analysts take longer to downgrade versus upgrade in a duration analysis framework. It is important to note that the return event cue is important even after controlling for the effect of other analysts' recommendation changes, suggesting that the cue is the primary motivating force behind the recommendation change rather than herding behavior.

\section{Additional Tests}

\section{A. Post-Event Returns}

The asymmetrical analyst response to large negative and positive return events does not rule out the possibility that analysts believe that they possess superior information. If analysts do believe that they have private information and their recommendations reflect it, then stock prices should adjust accordingly —on announcement of the recommendation change if markets are efficient, and in future periods if markets react to this information with a lag. We are particularly interested in determining whether analysts exhibit differential ability to predict future returns after downgrading following large negative news relative to other news/recommendation change combinations.

Table 7 presents unscaled mean and median equally weighted buy-and-hold market-adjusted returns following the 40,458 and 41,481 large negative and positive events. Returns are presented separately for recommendation changes of +1 and -1 , changes greater than (less than) or equal to $2(-2)$, and for no changes 
and affirmations, and over two different horizons, 20 days, and 60 days. Returns are computed as buy-and-hold returns on the day following the observed recommendation changes, as opposed to Womack (1996) who investigates the contemporaneous relation between returns and recommendation changes. ${ }^{18}$ Table 7 also presents tests of differences of mean and median returns following negative and positive return events for the same analyst response category.

TABLE 7

Future Market-Adjusted Returns Following Recommendation Changes (1\% Sample)

\begin{tabular}{|c|c|c|c|c|c|c|c|c|}
\hline \multirow{2}{*}{$\begin{array}{c}\text { Rec } \\
\text { Change }\end{array}$} & \multirow{2}{*}{$\begin{array}{l}\text { Return } \\
\text { Sign }\end{array}$} & \multirow[b]{2}{*}{ OBS } & \multicolumn{2}{|c|}{ Post 3 Days } & \multicolumn{2}{|c|}{ Post 20 Days } & \multicolumn{2}{|c|}{ Post 60 Days } \\
\hline & & & Mean & Median & Mean & Median & Mean & Median \\
\hline Down $\leq-2$ & $\begin{array}{l}\text { Negative } \\
\text { Positive } \\
\text { Difference }\end{array}$ & $\begin{array}{l}594 \\
208\end{array}$ & $\begin{array}{r}0.1 \% \\
-0.5 \% \\
0.6 \%\end{array}$ & $\begin{array}{c}-0.5 \%^{*} \\
-0.5 \%{ }^{*} \\
0.0 \%\end{array}$ & $\begin{array}{l}-0.2 \% \\
-2.7 \% \text { ** } \\
2.5 \%{ }^{* \star}\end{array}$ & $\begin{array}{c}-2.1 \%^{* *} \\
-2.1 \%^{* \star} \\
0.0 \%\end{array}$ & $\begin{array}{c}-3.0 \%^{* *} \\
-5.6 \%{ }^{* *} \\
2.7 \%\end{array}$ & $\begin{array}{c}-3.9 \% \%^{\star \star} \\
-5.4 \%{ }^{\star \star} \\
1.5 \%\end{array}$ \\
\hline Down -1 & $\begin{array}{l}\text { Negative } \\
\text { Positive } \\
\text { Difference }\end{array}$ & $\begin{array}{r}1,288 \\
359\end{array}$ & $\begin{array}{c}0.1 \% \\
-0.9 \%^{\text {** }} \\
1.1 \%{ }^{\text {** }}\end{array}$ & $\begin{array}{c}-0.5 \%^{*} \\
-1.0 \%{ }^{* \star} \\
0.5 \%\end{array}$ & $\begin{array}{l}-1.3 \% \text { ** } \\
-1.0 \% \\
-0.3 \%\end{array}$ & $\begin{array}{l}-2.2 \%^{\star \star} \\
-1.7 \% \%^{\star *} \\
-0.5 \%\end{array}$ & $\begin{array}{c}-3.3 \%{ }^{\star *} \\
0.2 \% \\
-3.5 \%{ }^{*}\end{array}$ & $\begin{array}{l}-3.9 \%^{\star \star} \\
-2.3 \%^{\star \star} \\
-1.6 \%\end{array}$ \\
\hline$U p+1$ & $\begin{array}{l}\text { Negative } \\
\text { Positive } \\
\text { Difference }\end{array}$ & $\begin{array}{l}424 \\
450\end{array}$ & $\begin{array}{r}0.4 \% \\
-0.1 \% \\
0.5 \%\end{array}$ & $\begin{array}{r}0.1 \% \\
-0.3 \% \\
0.4 \%\end{array}$ & $\begin{array}{c}0.4 \% \\
1.4 \%^{*} \\
-1.0 \%\end{array}$ & $\begin{array}{r}-0.1 \% \\
0.6 \% \\
0.7 \%\end{array}$ & $\begin{array}{c}-2.4 \%^{*} \\
3.1 \%^{*} \\
-5.5 \% \%^{* *}\end{array}$ & $\begin{array}{c}-2.6 \%^{\star \star} \\
1.5 \% \\
-4.1 \%^{\star \star}\end{array}$ \\
\hline$U p \geq+2$ & $\begin{array}{l}\text { Negative } \\
\text { Positive } \\
\text { Difference }\end{array}$ & $\begin{array}{l}122 \\
162\end{array}$ & $\begin{array}{r}0.2 \% \\
0.6 \% \\
-0.4 \%\end{array}$ & $\begin{array}{r}-0.3 \% \\
0.8 \% \\
-1.1 \%\end{array}$ & $\begin{array}{r}0.7 \% \\
1.8 \% \\
-1.1 \%\end{array}$ & $\begin{array}{c}0.8 \% \\
1.5 \%^{*} \\
-0.7 \%\end{array}$ & $\begin{array}{l}2.3 \% \\
0.0 \% \\
2.3 \%\end{array}$ & $\begin{array}{r}0.8 \% \\
-0.6 \% \\
1.4 \%\end{array}$ \\
\hline Affirm & $\begin{array}{l}\text { Negative } \\
\text { Positive } \\
\text { Difference }\end{array}$ & $\begin{array}{l}229 \\
132\end{array}$ & $\begin{array}{r}0.1 \% \\
-0.2 \% \\
0.2 \%\end{array}$ & $\begin{array}{r}-0.4 \% \\
0.3 \% \\
-0.7 \%\end{array}$ & $\begin{array}{l}-1.2 \% \\
-0.3 \% \\
-0.9 \%\end{array}$ & $\begin{array}{l}-1.3 \% \\
-0.6 \% \\
-0.7 \%\end{array}$ & $\begin{array}{l}-2.5 \% \\
-1.1 \% \\
-1.5 \%\end{array}$ & $\begin{array}{l}-3.8 \% \text { ** } \\
-1.9 \% \\
-1.9 \%\end{array}$ \\
\hline No change & $\begin{array}{l}\text { Negative } \\
\text { Positive } \\
\text { Difference }\end{array}$ & $\begin{array}{r}111,292 \\
98,824\end{array}$ & $\begin{array}{r}0.2 \%^{* *} \\
-0.5 \%^{\text {** }} \\
0.7 \%^{* *}\end{array}$ & $\begin{array}{r}0.0 \%^{* *} \\
-0.6 \%^{* *} \\
0.6 \%^{* *}\end{array}$ & $\begin{array}{c}-0.3 \%^{\text {** }} \\
-0.5 \%^{\text {** }} \\
0.2 \%^{\text {** }}\end{array}$ & $\begin{array}{r}-0.5 \%^{* *} \\
-0.9 \%^{* *} \\
0.4 \%^{* *}\end{array}$ & $\begin{array}{l}-1.1 \%^{* *} \\
-0.6 \%^{* *} \\
-0.5 \%^{* *}\end{array}$ & $\begin{array}{r}-1.7 \%^{\star \star} \\
-2.2 \%^{\text {** }} \\
0.5 \%^{\text {** }}\end{array}$ \\
\hline
\end{tabular}

Table 7 presents market-adjusted buy-and-hold returns over the corresponding three-, 20- and 60-day periods beginning the day after the corresponding recommendation change. The return sign is designated positive (negative) if $A D J R E T 3$ is greater than or equal to (less than) zero. Rec Change represents the corresponding recommendation change that occurs the day after the large return event ends. The Difference row provides tests of differences between the same categories across different return signs. * ${ }^{* *}$ indicate two-tailed $t$-statistic significance at the $5 \%$ and $1 \%$ levels, respectively.

The general picture that emerges is that stock prices drop immediately around downgrades, and continue to fall in the days following downgrades regardless of whether the downgrade was preceded by a large positive or negative return event. For example, Table 7 reveals that median returns for stocks that are downgraded one category, which comprise more than two-thirds of the downgrades, are significantly negative over the 20- and 60-day horizons following both negative and positive return events. ${ }^{19}$ Similar findings obtain for stocks that are downgraded two or more categories. There is no systematic stock price movement following upgrades preceded by either large positive or negative return events. ${ }^{20}$ The tests for differences in mean returns in Table 7 indicate that, if anything, negative price

\footnotetext{
${ }^{18}$ We also examined post-event returns conditioning on the sign of unexpected recommendation changes computed using fitted values from the probit model. Untabulated findings reveal no observable pattern in post-event returns that cannot be garnered from the tabulated results in Table 7.

${ }^{19}$ Insignificance in some of the mean returns is likely attributable to positive return skewness. Extant research (Kothari and Warner (1997)) suggests that skewness is not peculiar to our sample, but is endemic to buy-and-hold returns.

${ }^{20}$ One interesting finding is that stock prices appear to fall for "no change" observations preceded by both large positive and negative return events. One explanation for this is that the market expected most of these stocks to have been upgraded. That is, the fact that such stocks were not upgraded was regarded as bad news by the market.
} 
reactions are stronger following downgrades $(-2.7 \%)$ preceded by positive return events than negative return events $(-0.2 \%)$. That is, we do not find evidence that the larger propensity for analysts to downgrade following large negative price shocks is attributable to the analysts' ability to predict that the prices will continue to fall.

Taken together, the evidence in Table 7 seems to provide support for the notion that analyst recommendation changes (more specifically, the downgrades) following large stock price movements are informative to the market. However, the future return data fail to account for asymmetrical response of analysts in response to large negative and positive stock price events. ${ }^{21}$ That is, for our sample of large stock price events, we find no basis in subsequent returns for the differences in analysts' response to a sharp price movement.

\section{B. Earnings Announcement Events}

As an additional robustness check, we re-estimated the probit model on a subsample of earnings announcement events. Specifically, instead of using large price changes to define our sample, we use the sample of all earnings announcement events for firms in our sample. Our purpose in conducting this test is to choose a sample of price movements for which we know there is a corresponding information event. We record all analyst recommendations in the 15 days following each earnings announcement. For the earnings announcement subsample, $58 \%$ of recommendation changes occur in the three days immediately following the earnings announcement.

In this probit analysis we control for the sign and magnitude of the earnings surprise measured for each individual analyst. We also interact the extent of the earnings surprise with the related price response. Untabulated results indicate that analysts are still more likely to downgrade following a large negative stock price shock. That is, controlling for the sign and magnitude of the earnings surprise has no effect on inferences from our main findings reported in Tables 5 and $6 .{ }^{22}$

\section{Conclusion}

This study examines how analysts respond to public information when setting their stock recommendations. Specifically, we empirically test different hypotheses regarding analyst information and incentives using a sample of stocks that experience large stock price movements, and analyst recommendation changes for those stocks. Using an ordered probit model based on all available IBES stock

\footnotetext{
${ }^{21}$ Untabulated findings from additional analyses provide some evidence that controlling for analyst activity during future return event horizons accounts for part of the returns following the recommendation change events.

${ }^{22}$ As another robustness check, we re-estimated the probit model for a subsample of large return events for which we could find no public information release (see footnote 9 for a description of this subsample). In this subsample, it is less likely that fundamental value, and hence analysts' fundamental valuation, changes. In this subsample of 500 large return events, there were 97 large stock price movements for which we could find no related public release of news. For these 97 events, there were five (12) analysts who changed their recommendation in the five (10) days following the large return event. The results from this estimation are similar to those reported in the paper, and suggest that it is the return event and not just the public news that causes the asymmetry in analysts' response.
} 
recommendations from 1993 to 1999, we find evidence of an asymmetry between the results for positive and negative returns, even after controlling for the initial recommendation level. Following large positive returns, the probability of upgrades and downgrades is about equal. In contrast, following large negative returns, analysts are much more likely to downgrade than upgrade the company's stock.

Our findings are consistent with the hypothesis that analysts believe that they have private information, and set recommendations comparing private values to market price. That is, they respond to public information events using large price shocks as a proxy for news. However, the asymmetrical response is further consistent with a dynamic component to the analyst's optimism when setting recommendations. The results suggest stickiness in recommendations induced by reluctance to downgrade, possibly because of conflicts of interest or information cascades.

Relatedly, there is also evidence that upgrades are more likely if there is an investment banking relationship between the brokerage firm making the recommendation and the firm for which the recommendation is issued. In addition, there is evidence that analysts tend to respond in the same direction as other analysts who recently changed their recommendations, which adds some support for the notion of herding among analysts. This finding obtains for the full sample of recommendations, and (as a control for the censored nature of the recommendation levels, and changes in levels) for a subsample that includes only "interior" recommendation levels of 2,3 , or 4 .

Findings from analysis of future stock returns indicate that analysts' recommendation changes are useful in explaining future stock returns. However, the findings fail to provide an explanation for the observed asymmetry in the response of analysts following large negative and positive return events. Specifically, we find no evidence that the market consistently under- or over-reacts to public information. We also examine a subset of recommendations following large stock price movements that are associated with earnings announcements and find the asymmetry is present in this subsample. That is, after controlling for earnings surprises, downgrades are more likely to follow negative price shocks, but upgrades and downgrades are equally likely to follow positive price shocks. Overall, our findings suggest that the bias in recommendations changes through time, and that the bias may decrease conditional on a significant public information shock.

\section{References}

Barber, B. M.; R. Lehavy; and B. Trueman. "Comparing the Stock Recommendation Performance of Investment Banks and Independent Research Firms." Working Paper, Univ. of California, Los Angeles (2004).

Bikhchandani, S.; D. Hirshleifer; and I. Welch. "A Theory of Fads, Fashion, Custom, and Cultural Change as Informational Cascades.” Journal of Political Economy, 100 (1992), 992-1026.

Block, S. B. "A Study of Financial Analysts: Practice and Theory." Financial Analysts Journal, 55 (1999), 86-95.

Blume, M., and R. F. Stambaugh. "Biases in Computed Returns: An Application to the Size Effect." Journal of Financial Economics, 12 (1983), 387-404.

Boni, L., and K. L. Womack. "Analysts, Industries, and Price Momentum." Journal of Financial and Quantitative Analysis, 41 (2006), 85-109. 
Bradshaw, M. T. "How Do Analysts Use Their Earnings Forecasts in Generating Stock Recommendations?" Accounting Review, 79 (2004), 25-50.

Cornell, B. "Is the Response of Analysts to Information Consistent with Fundamental Valuation: The Case of Intel." Financial Management, 30 (2001), 113-136.

Finger, C., and W. R. Landsman. "What Do Analysts' Stock Recommendations Really Mean?" Review of Accounting and Finance, 2 (2003), 65-85.

Green, T. C. "The Value of Client Access to Analyst Recommendations." Journal of Financial and Quantitative Analysis, 41 (2006), 1-24.

Green, W. H. Econometric Analysis, 3rd ed. Upper Saddle River, NJ: Prentice Hall (1997).

Hong, H., and J. Kubik. "Analyzing the Analysts: Career Concerns and Biased Earnings Forecasts." Journal of Finance, 58 (2003), 313-351.

Hong, H.; J. Kubik; and A. Salomon. "Security Analysts' Career Concerns and Herding of Earnings Forecasts." RAND Journal of Economics, 31 (2000), 121-144.

Houston, J.; C. James; and J. Karceski. "What a Difference a Month Makes: Stock Analyst Valuations Following Initial Public Offerings.” Journal of Financial and Quantitative Analysis, 41 (2006), 111-137.

Jegadeesh, N., J. Kim, S. Krische, and C. M. C. Lee. "Analyzing the Analysts: When Do Recommendations Add Value?” Journal of Finance, 59 (2004), 1083-1124.

Kothari, S. P., and J. B. Warner. "Measuring Long-Horizon Security Price Performance.” Journal of Financial Economics, 43 (1997), 301-339.

Lin, H., and M. F. McNichols. "Underwriting Relationships, Analysts' Earnings Forecasts and Investment Recommendations." Journal of Accounting and Economics, 25 (1998), 101-127

Lin, H.; M. F. McNichols; and P. C. O'Brien. "Analyst Impartiality and Investment Banking Relationships." Working Paper, Stanford Univ. (2004).

The New York Times. “30 States Join Wall Street Probe,” May 24, 2002.

Ohlson, J. A. "Earnings, Book Values, and Dividends in Equity Valuation." Contemporary Accounting Research, 11 (1995), 661-687.

Opdyke, J. D. "Many Analysts Found to Invest In the Companies They Covered." The Wall Street Journal, August 1, 2001, C1.

Ryan, P., and R. J. Taffler. "Are Economically Significant Stock Returns and Trading Volumes Driven by Firm-Specific News Releases?” Journal of Business Finance \& Accounting, 31 (2004), 49-82.

Stickel, S. E. "The Anatomy of the Performance of Buy and Sell Recommendations." Financial Analysts Journal, 51 (1995), 25-39.

Tully, S. "Betrayal on Wall Street." Fortune Magazine, May 14, 2001, 98-103.

Welch, I. "Herding among Security Analysts." Journal of Financial Economics, 58 (2000), 369-396.

Womack, K. L. “Do Brokerage Analysts' Recommendations Have Investment Value?" Journal of Finance, 51 (1996), 137-167. 